\title{
Thermodynamic analysis of design and part- load operation of a novel waste heat recovery unit
}

\author{
Aleksandr Sebelev ${ }^{1, *}$, Aleksandr Kirillov ${ }^{1}$, Gennadii Porshnev $^{1}$, Kirill Lapshin ${ }^{1}$, and \\ Aleksandr Laskin ${ }^{1}$ \\ ${ }^{1}$ Peter the Great St. Petersburg Polytechnic University, Polytechnicheskaya 29, St. Petersburg, \\ 195251, Russian Federation
}

\begin{abstract}
Organic Rankine Cycle (ORC) thermodynamic optimization is of critical importance while developing new plants. Optimization procedures may be aimed at the highest efficiency as well as cost or sizing minimization. Optimization process is generally carried out for plant nominal rating. At the same time, part-load operation has to be carefully considered in case of waste heat recovery from flue gases coming from internal combustion engines or gas turbines. Gas mass flow and temperature variations are specific to this application, significantly influencing ORC plant performance. Secure prediction of part-load operation is of particular importance for assessment of plant power output, providing stability and safety and utilizing proper control strategy. In this paper design and off-design cycle simulation model is proposed. Offdesign performance of the ORC cycle recovering waste heat from gas turbine unit installed at gas compressor station is considered. Major factors affecting system performance are outlined.
\end{abstract}

\section{Introduction}

Waste heat recovery is a growing market with an upward trend of new plants construction as can be seen into the ORC worldwide map [1]. Waste heat recovery is provided by ORC technology that has being developed over the last 30 years. The two major directions for its further development can be outlined. The first one is working fluid selection and thermodynamic optimization of an ORC cycle at design and part-load operation. The second one is ORC expansion units improvement arising from their current low efficiency due to high Mach numbers and complex organic fluids behavior [2, 3].

The current paper deals with the first issue. Plenty of novel mediums have appeared over the last decade, like siloxanes and zeotropic mixtures, which can provide significant increase of a cycle efficiency up to $20-25 \%$ [4, 5], therefore fluid selection is important part of a plant design.

Simulation of a part-load ORC operation is a relevant problem that attracts attention of many researchers $[6,7,8,9,10]$. Fu et al. [7] describes a heat transfer model for off-design

*Corresponding author: a.sebelev.turbo@mail.ru 
ORC operation, cycle efficiency was not considered. Paper presented by Munoz de Escalona et al. [9] is dedicated to analysis of a joint operation of a gas turbine and waste heat recovery ORC unit with using commercial software. La Seta et al. [11] have shown that while turbine efficiency is incorporated in ORC performance model the optimum efficiency may occur within lower pressure ratios than it is predicted without turbine consideration. The latter highlight the significance of off-design simulation accounting expander performance. Calise et al. [6] and Manente et al. [8] proposed ORC part-load operation in-house analysis tools. In interesting fact is that different approaches are implemented by different authors in terms of expander part-load performance, which corroborates that one-size-fits-all solution does not exist and further investigations are still relevant [25-30].

\section{Methods}

\subsection{Investigation object}

An ORC cycle for waste heat recovery from gas turbine unit at gas compression station is considered in the current paper, which comprehensive description and justification of the conceptual design was provided by Zabelin et al. [12]. Due to the particularities of gas transmission system the said plant operates mostly at part-load. Part-load operation and wide range of ambient temperatures result in significant variation of mass flow rate and temperature of flue gases, directly influencing ORC efficiency and power output.

The nominal rating power of the ORC plant is $500 \mathrm{~kW}$. The cycle is driven with octamethyltrisiloxane (MDM). Flue gases leaving a gas turbine have a temperature between 653 and $763 \mathrm{~K}$, depending on season and loading. The ORC system layout is presented in figure 1, thermodynamic cycle in T-s diagram is depicted in figure 2 and has the particularities as follows:

1) interim circuit with diathermic oil is comprised into the system.

2) the presence of a regenerator;

3) turbine bypass line is arranged in accordance with the control algorithm;

4) possibility of working in CHP mode.

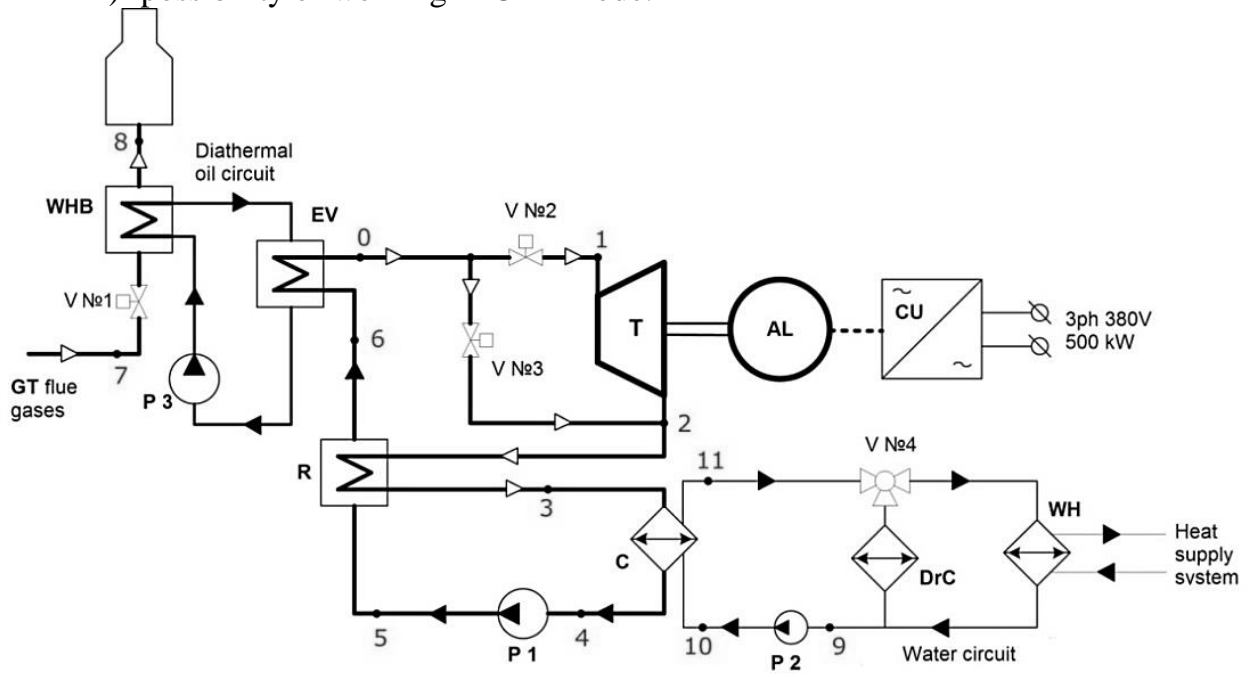

Fig. 1. ORC plant outline: DrC - dry cooler; $\mathrm{WH}$ - water heater; $\mathrm{CU}$ - control unit; GT - gas turbine; $\mathrm{E}$ - evaporator; C - condenser; WHB - waste heat recovery boiler; V №1 - V №3 - valves; P1 - P3 - pumps; AL - alternator; $\mathrm{T}$ - turbine; $\mathrm{R}$ - regenerator 
Interim circuit is used so as to prevent working fluid from thermal decomposition due to direct heating from high temperature flue gases [13, 14]. Regenerator enables higher efficiency for siloxane fluids with an expansion process termination far from a saturation curve [15]. Several investigations state that regenerator does not alter the plant cost and is favorable while flue gas higher temperature is limited [16, 17].

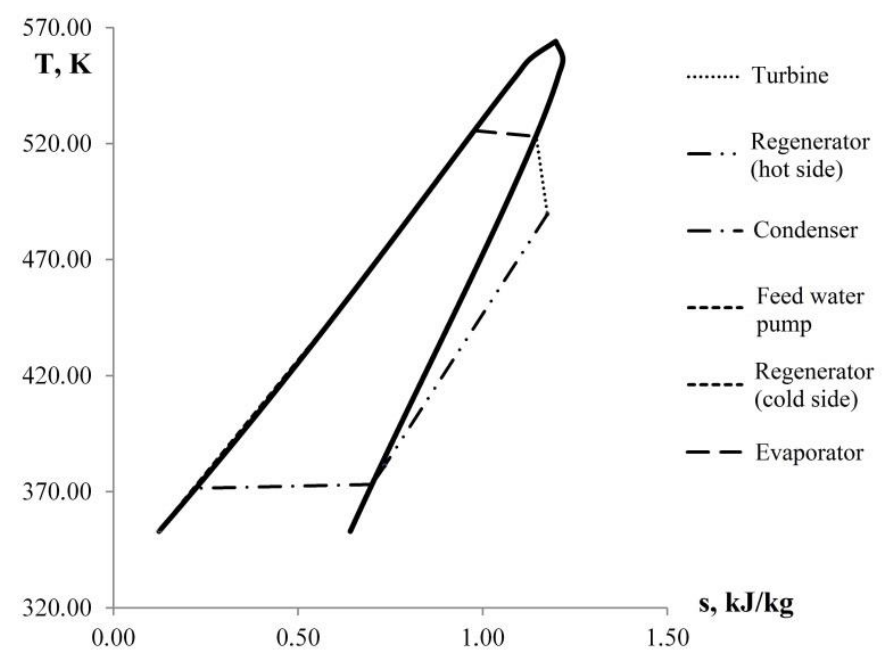

Fig. 2. The thermodynamic cycle

Bypass line is aimed at realization of ORC plant part-load operation. A drop of parameters at point " 0 " corresponds to a decrease of flue gases mass flow $G_{\mathrm{FG}}$ and temperature $T_{\mathrm{FG}}$ so as to provide working fluid evaporation. In this, turbine inlet pressure lowers causing respective drop in a mass flow compared with a design point value. In order to meet lower mass flow rates at part-load operation bypass line is arranged.

Finally, condensation pressure limitation exists as a result of providing heat power supply with using condenser heat. The heating control curve (temperatures at supply and return lines) is set by the Russian statutory documents [18], requiring $95^{\circ} \mathrm{C}$ at the supply line for the lowest ambient temperature.

As a result of a cycle optimization, provided below, and with respect to the abovementioned restrictions the following cycle parameters are set for the design point:

- $\quad$ turbine inlet pressure $p_{0}{ }^{*}=0.75011 \mathrm{MPa}$, inlet temperature $T_{0}{ }^{*}=523.15 \mathrm{~K}$;

- condensation pressure $p_{2}=0.020163 \mathrm{MPa}$.

Despite the fact that the back pressure is below the ambient one, no deaerator is used, which is in line with the contemporary practice [19]. Placing the turbine inlet point into subcritical area aimed at providing thermal stability of the working fluid and discarding intricate turbine blade shaping [20,21].

\subsection{Mathematical model}

Enthalpy method, described by Barilovich and Smirnov [22] is a basis of the implemented mathematical model. The governing equations were used as follows:

$$
\begin{gathered}
h_{2}^{\prime \prime}=h_{0}+\eta_{T}\left(h_{2}^{d s=0}-h_{0}\right) \\
h_{2}=G_{T} h_{2}^{\prime \prime}+h_{0}\left(G^{n o m}-G_{T}\right)
\end{gathered}
$$




$$
\begin{aligned}
& G^{n o m}=\frac{N^{n o m}}{\left(h_{2}^{\prime \prime}-h_{1}\right) \eta_{m e c h} \eta_{A L}-\left(h_{5}-h_{4}\right)} \\
& G_{T}=G^{n o m} \sqrt{\left(1-\frac{\left(\frac{p_{1}}{p_{2}^{\prime \prime}}-\left(\frac{p_{1}}{p_{2}^{\prime \prime}}\right)_{c r}\right)^{2}}{\left(\left(\frac{p_{1}}{p_{2}^{\prime \prime}}\right)_{c r}-1\right)^{2}} \frac{T_{0}^{n o m}}{T_{0}}\right.} \\
& \eta_{T}=-\frac{\eta_{T}^{\text {nom }}}{\left(u / C_{0}\right)_{\text {nom }}}\left(\frac{\left(u / C_{0}\right)^{2}}{\left(u / C_{0}\right)_{n o m}}-\frac{2 u}{C_{0}}\right) \\
& h_{5}=h_{4}+\frac{\left(h_{5}^{d s=0}-h_{4}\right)}{\eta_{P}} \\
& G_{\text {hot }}\left(h_{\text {hot }}^{\text {in }}-h_{\text {hot }}^{\text {out }}\right) \mu=G_{\text {cold }}\left(h_{\text {cold }}^{\text {in }}-h_{\text {cold }}^{\text {out }}\right) \\
& k F=\sum_{i} \frac{\dot{Q}_{i}}{\theta_{i}} \\
& \eta_{\text {tot }}=\frac{G_{T}\left(h_{2}^{\prime \prime}-h_{1}\right) \eta_{m e c h} \eta_{A L}-G^{\text {nom }}\left(h_{5}-h_{4}\right)}{G_{f g}\left(h_{f g}^{\text {in }}-h_{f g .}^{\text {out }}\right)}
\end{aligned}
$$

$k F$ criterion is obtained as a sum from all the plant exchangers.

\subsection{Optimization strategy}

The optimization is carried out through the in-house analysis tool developed by Polytechnic university, which complete description and verification was provided by Sebelev et al. [23]. Since the turbine back pressure is restricted by heat supply as described above, the optimization is carried out in terms of defining point $0\left(p_{0}{ }^{*}, T_{0}{ }^{*}\right)$. All the other parameters are set constant for the design point. A range of pressures and temperatures is considered for simple and regenerated cycles. The optimization goal is the highest cycle efficiency within reasonable heat exchangers sizing and taking into account the restrictions on the heat source. The maximum flue gases mass flow rate is $13 \mathrm{~kg} / \mathrm{s}(60 \%$ of the nominal outlet mass flow rate) and its minimum temperature after the evaporator (superheater) is $150^{\circ} \mathrm{C}$ with due regard for the corrosion protection of the exhaust system [24].

\subsection{Part-load operation simulation strategy}

Essentially, the major issue of thermodynamic cycle part-load operation modeling is in defining the point $0\left(p_{0}{ }^{*}, T_{0}{ }^{*}\right)$, figure 3 , so as the amount of heat at part-load operation is sufficient for fluid evaporation and overheating corresponding this point. Since point 0 parameters and turbine part-load efficiency define the fluid enthalpy at the turbine outlet, and then at the evaporator inlet, the iteration approach is carried out in the current study. The point 0 is set first and then the 'evaporation balance' $\delta_{e v}$, equation (10) is controlled.

$$
\delta_{e v}=Q_{E}+Q_{R}-\left(h_{1}-h_{5}\right)
$$




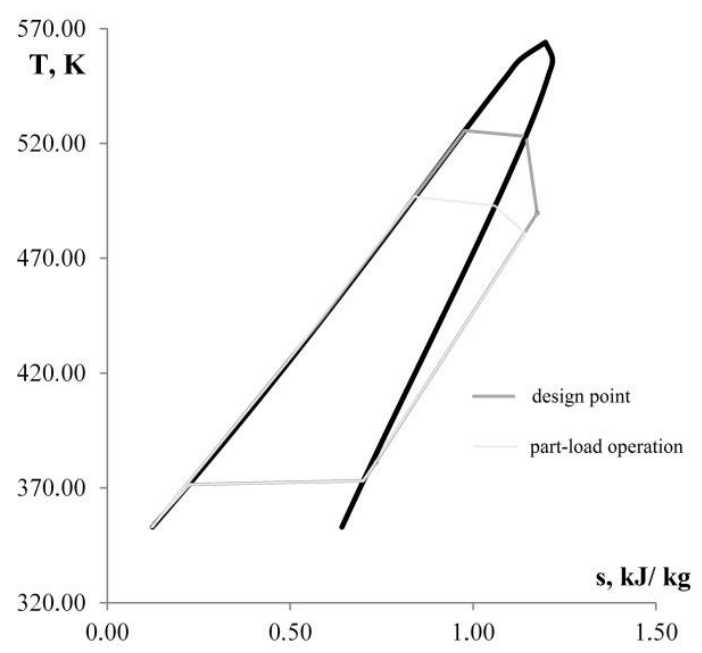

Fig. 3. Comparison of the cycle design and part-load operation

Positive values of $\delta_{e v}$ mean that the point 0 parameters have to be increased, and vice versa. For simplicity, point 0 is set to be on the saturation curve. The flue gases temperature range from 380 to $450^{\circ} \mathrm{C}(653$ to $723 \mathrm{~K})$ is considered within the mass flow rate range between 9 and $13 \mathrm{~kg} / \mathrm{s}$.

\section{Results and discussion}

\subsection{Cycle optimization}

The two-parameter plots of total efficiency, required flue gases mass flow rate and $k F$ coefficient versus initial pressure $p_{0}{ }^{*}$ and initial temperature $T_{0}{ }^{*}$ are provided in figures 4,5 and 6. Overall efficiency soars if the regenerator is incorporated into the cycle showing $6 \%$ increase in absolute figures. An interesting fact is that $\eta_{\text {tot }}$ behavior is qualitatively different for the cycle with and without regeneration. In the first case, there is no efficiency increase with rise of temperature, while it exists in regenerated cycle as depicted in figure 4.

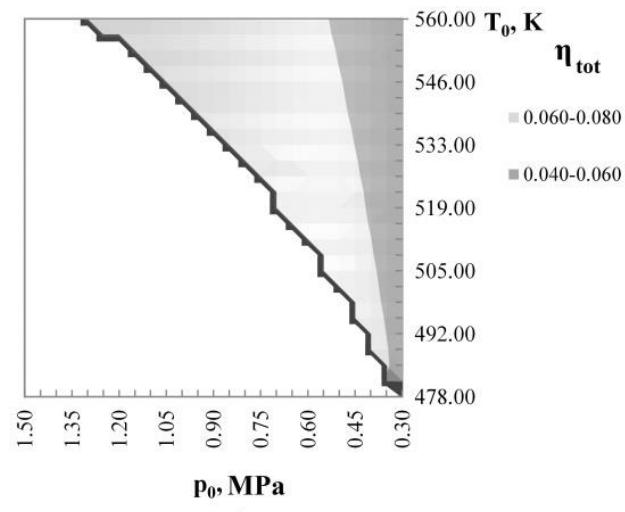

a)

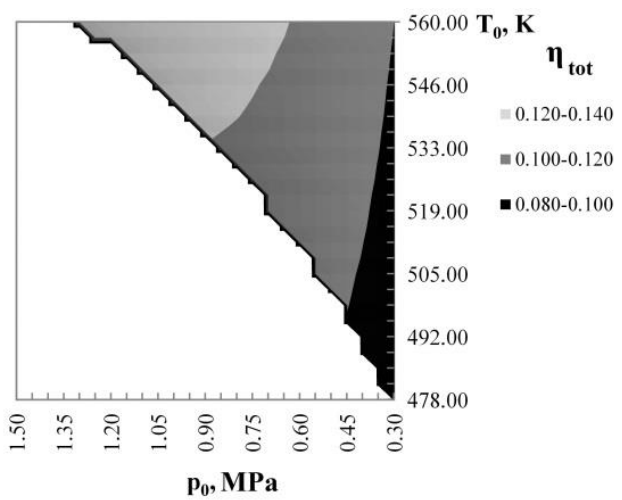

b)

Fig. 4. ORC plant total efficiency $\eta_{\text {tot }}$ versus point 0 parameters for simple (a) and regenerated (b) cycle 
Simple cycle requires flue gas mass flow rates above the limit of $13 \mathrm{~kg} / \mathrm{s}$ and therefore is not applicable. Regenerated cycle is favorable in terms of flue gases decreasing. As a drawback almost twofold increase of heat exchanger $k F$ criterion is observed due to the temperature head drop in interim oil circuit and evaporator and additional area of the regenerator as shown in figure 5 .

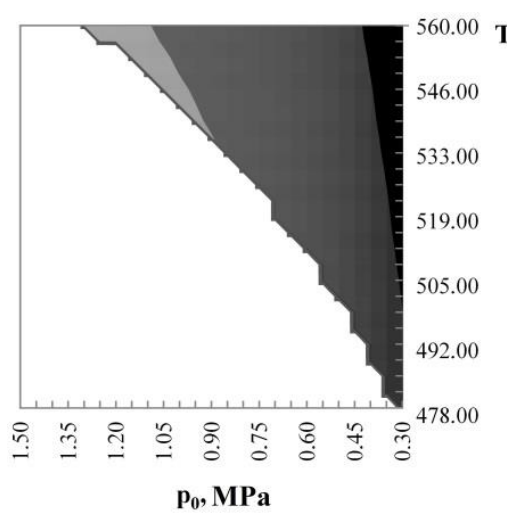

a)

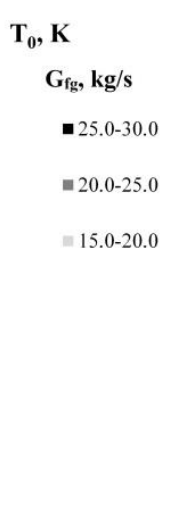

$\mathrm{G}_{\mathrm{fg}}, \mathrm{kg} / \mathrm{s}$

$20.0-25.0$

$15.0-20.0$

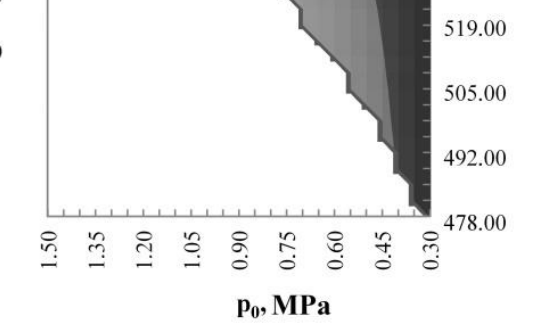

b)

Fig. 5. Flue gases mass flow required versus point 0 parameters for simple (a) and regenerated (b) cycle

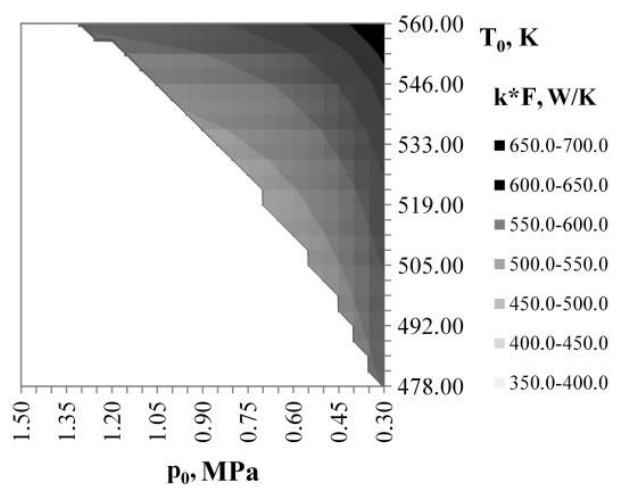

a)

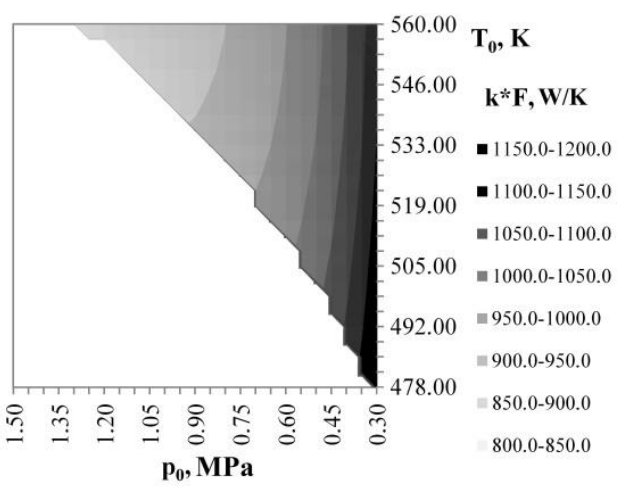

b)

Fig. 6. $k F$ parameters versus point 0 parameters for simple (a) and regenerated (b) cycle

Critical influence of the back pressure $p_{2}$ on the total efficiency $\eta_{t o t}$ is observed which positively correlates with the basic theory of a Rankine Cycle [22]. Twofold increase of the required flue gases mass flow rate and threefold drop of the total efficiency $\eta_{\text {tot }}$ occurs within the back pressure range $p_{2}$ from 0.02 to $0.1 \mathrm{MPa}$ as shown in figure $7 \mathrm{a}$. Thus, the lower $p_{2}$ value was set for the cycle operation.

The impact of the flue gases temperature on the cycle performance was also considered. The temperature range was set in accordance with the performance data of gas turbine unit. The heat exchanger $k F$ criterion does not show substantial dependency on the temperature, while the flue gases mass flow rate experiences a $18.5 \%$ growth within the temperature range in question. The abovementioned trends are shown in figure $7 \mathrm{~b}$.

A critical fact is that during the primary gas turbine operation pares of its flue gases temperatures $T_{\mathrm{FG}}$ and mass flow rates $G_{\mathrm{FG}}$ appear that are not able to provide nominal ORC plant power. It is even more vital in case of autonomous plant operation while electrical 
grid backup is not possible. On this account, a careful consideration of part-load operation is crucial in order to find secure correlations between gas turbine outlet conditions and the ORC cycle efficiency and power output.

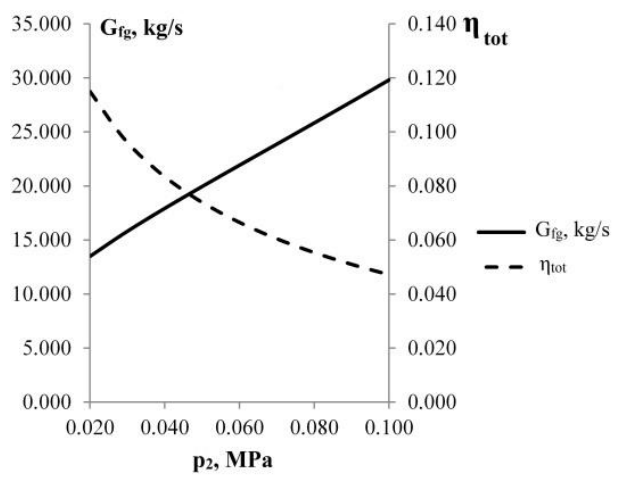

a)

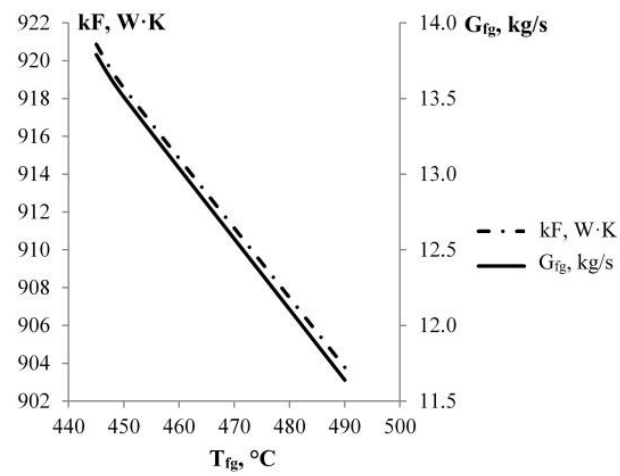

b)

Fig. 7. Effect of back pressure $p_{2}$ and flue gases temperature $T_{\mathrm{FG}}$ on the cycle performance

\subsection{Cycle part-load operation analysis}

Cycle total efficiency and power output plots are presented in figure 8. Temperature drop to $400^{\circ} \mathrm{C}(673 \mathrm{~K})$ causes twofold drop of the efficiency (up to $6 \%$ ), while the power does not exceed $250 \mathrm{~kW}$. This operational point corresponds to a loading of the primary gas turbine unit of $50 \%$ and less.

For the gas turbine power range from 50 to $100 \%$ a significant effect of the flue gases mass flow rate is clearly observed. $40 \%$ drop of the output power corresponds to $10 \%$ decrease of $G_{\mathrm{FG}}$, while the overall efficiency tends not to exceed $8 \%$ in this case. Within the temperature range from 400 to $450^{\circ} \mathrm{C}$ the $\mathrm{ORC}$ plant is not functional when a $25 \%$ drop of the mass flow rate occurs.

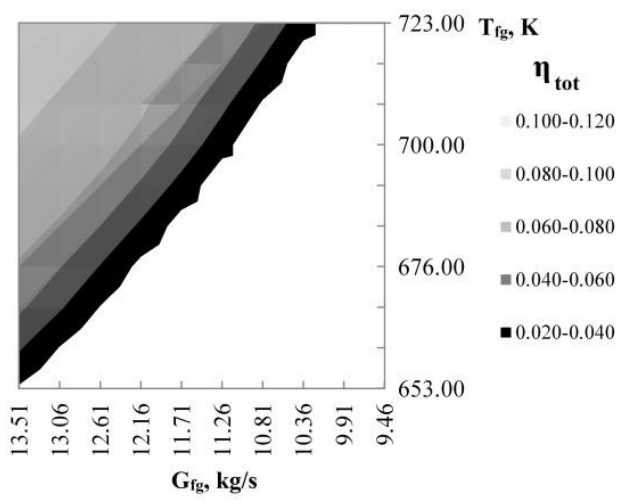

a)

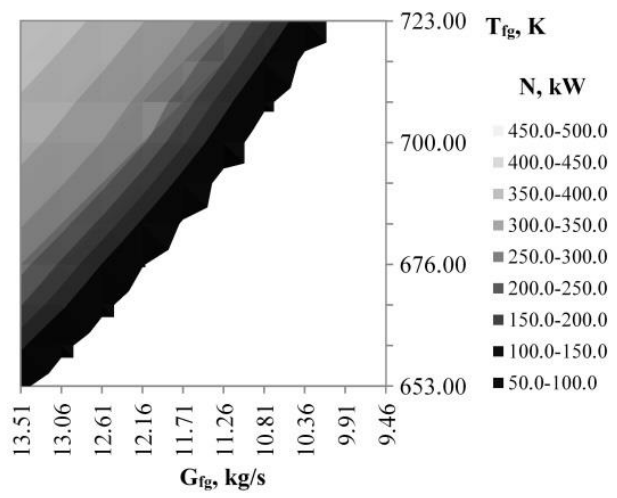

b)

Fig. 8. ORC plant total efficiency $\eta_{t o t}$ (a) and plant power (b) versus flue gases temperature $T_{\mathrm{FG}}$ and mass flow rate $G_{\mathrm{FG}}$ 


\section{Conclusions}

Design and off-design simulation of the ORC cycle recovering flue gases waste heat through the in-house software is presented in the current paper. Cycle optimization procedure for the design point is provided. It is shown that for the chosen working fluid regenerator significantly contributes to cycle efficiency, increasing, however, the heat exchanger $k F$ coefficient. An iteration approach is proposed in order to solve the off-design cycle simulation problem expressed in defining the parameters at point 0 . It is shown that in case of flue gases waste heat recovery the gases mass flow rate is predominant for the cycle performance.

\section{Nomenclature}

$\begin{array}{ll}G & \text { mass flow rate }(\mathrm{kg} / \mathrm{s}) \\ H & \text { enthalpy }(\mathrm{kJ} / \mathrm{kg}) \\ h^{\prime \prime}{ }_{2} & \text { actual enthalpy at point } 2(\mathrm{~kJ} / \mathrm{kg}) \\ k F & \text { heat exchanger sizing criterion } \\ p & \text { pressure }(\mathrm{MPa}) \\ Q & \text { heat flux }(\mathrm{W}) \\ S & \text { entropy }(\mathrm{kJ} / \mathrm{kg} \cdot \mathrm{K}) \\ T & \text { temperature }(\mathrm{K}) \\ u / C_{0} & \text { stage specific speed } \\ \eta & \text { efficiency } \\ \Theta & \text { logarithmic mean temperature }(\mathrm{K}) \\ M & \text { heat exchanger recovery factor }\end{array}$

$\begin{array}{ll}\text { Subscript and abbreviations } \\ \text { AL } & \text { alternator } \\ c r & \text { critical } \\ \text { fg } & \text { flue gases } \\ \text { mech } & \text { mechanical (efficiency) } \\ \text { nom } & \text { nominal rating } \\ P & \text { pump } \\ \text { tot } & \text { total } \\ \text { in } & \text { inlet } \\ \text { out } & \text { outlet } \\ \text { cold } & \text { referring to high temperature } \\ & \text { side of a heat exchanger } \\ \text { hot } & \text { referring to high temperature } \\ & \text { side of a heat exchanger }\end{array}$

\section{References}

1. World map of ORC installations. Online source. http://orc-world-map.org/

2. P. Klonowicz, F. Hereble, M. Preißinger, D. Brüggemann. Energy. 72. p. 322 330. (2014).

3. A.P. Weiß. Proc. of 3rd Int. Seminar on ORC Power Systems. Paper ID: 22. (2015).

4. M. Chys, M. van den Broek, B. Vanslambrouck, M. De Paepe. Energy. 44. p.623632. (2012).

5. A. Uusitalo, T. Turunen-Saaresti, J. Honkatukia, P. Colonna, J. Larjola. J. of Engineering for Gas Turbines and Power. 135. 042305. (2013).

6. F. Calise, C. Capuozzo, A. Carotenuto, L. Vanoli. Solar Energy. 103. p.595-609. (2014).

7. B.-R. Fu, Ch.-H. Li. Proc. of 1st Int. e-Conf. on Energies. (2014).

8. G. Manente, A. Toffolo, A. Lazzaretto, M. Pac. Energy. 58. p.97-106. (2013).

9. J.M. Munoz de Escalona, D. Sanchez, R. Chacartegui, T. Sanchez. Applied Thermal Engineering. 36. p. 63-72. (2012).

10. H.T. Walnum, D. Rohde, Y. Ladam. Int. J. of Low-Carbon Technologies. 0. p.1-8. (2012).

11. A. La Seta, A. Meroni, J.G. Andreasen, L. Pierobon, G. Persico, F. Haglind. Energies. 9 (6). p. 393. (2016). 
12. N.A. Zabelin, A.A. Sebelev, M.V. Smirnov, A.S. Saichenko. Gas Industry Magazine. 9 (743). p.28-36. (2016).

13. C.M. Invernizzi, P. Iora, M. Preißinger, G. Manzolini. Applied Thermal Engineering. 103. p.790-797. (2016).

14. M. Preißinger, D. Brüggemann. Energies. 9 (183). (2016).

15. I. Vankeirsbilck, B. Vanslambrouck, S. Gusev, M. De Paepe. Proc. of 8th International Conference on Heat Transfer, Fluid Mechanics and Thermodynamics. p.785-792. (2011).

16. S. Lecompte, H. Huisseune, M. van den Broek, B. Vanslambrouck, M. De Paepe. Renewable and Sustainable Energy Reviews. 47. p.448-461. (2015).

17. D. Maraver, J. Royo, V. Lemort, S. Quoilin. Applied Energy. 117. p.11-29. (2014).

18. SP 60.13330.2012. (Russian statutory document). Heat supply, ventilation and airconditioning. An updated version of SNiP 41-01-2003.

19. T. Turunen-Saaresti, A. Uusitalo, J. Honkatukia. IOP Conf. Series: Journal of Physics: Conf. Series. 821. (2017).

20. E.A. Bufi, B. Obert, P. Cinella, M. De Paepe. Proc. of 3rd Int. Seminar on ORC Power Systems. Paper ID: 34. (2015)

21. B. Bülten, W. Althaus, E. Weidner, H. Stoff. Proc. of 11th European Conference on Turbomachinery Fluid dynamics \& Thermodynamics. (2015).

22. V.A. Barilovich, Yu.A. Smirnov. Principles of thermodynamic and theory of heatand- mass transfer. Saint-Petersburg, Polytechnic University publishing. (2010).

23. A. Sebelev, R. Scharf, M. Smirnov, N. Zabelin. Proc. of $12^{\text {th }}$ Int. Symposium on Experimental and Computational Aerothermodynamics of Internal Flows. ISAIF12-142. (2015).

24. L.N. Sidelnikovsy, V.N. Yurenev. Industrial boiler installations: higher school textbook. Moscow. Energoatomizdat. third edition. (1988).

25. J. Saari, E.Sermyagina, J.Kaikko, E.Vakkilainen, V. Sergeev. Energy. 113 (2016)

26. I.D. Anikina, V.V. Sergeyev, N.T. Amosov, M.G. Luchko. International Journal of Hydrogen Energy, 42 (1) (2017)

27. N.D. Agafonova, M.Y. Egorov, V.V. Sergeev, M.A. Gotovskii, P.A. Kruglikov, M.E. Lebedev, A.V. Sudakov, E.D. Fedorovich, B.S. Fokin. Atomic Energy. 123 (3) (2018)

28. A. Bolotin, V. Bakayev. Journal of Human Sport and Exercise (2017)

29. V.P. Sushchenko, V.A. Shchegolev, A.V. Korshunov. Teoriya i Praktika Fizicheskoy Kultury (2016)

30. A.A. Sebelev, A.S. Saychenko, N.A. Zabelin, M.V. Smirnov, St. Petersburg State Polytechnic University Journal of Engineering Science and Technology, 3(249), 29-38 (2016) 